\title{
FEM performance of concrete beams reinforced by carbon fiber bars
}

\author{
Hashim Hasan \\ Building and Construction Engineering Department, University of Technology, Baghdad, Iraq
}

\begin{abstract}
Concrete structures may be vulnerable to harsh environment, reinforcement with Fiber Reinforced Polymer (FRP) bars have an increasing acceptance than normal steel. The nature of (FRP) bar is (non-corrosive) which is very beneficial for increased durability as well as the reinforcement of FRP bar has higher strength than steel bar. FRP usage are being specified more and more by public structural engineers and individual companies as main reinforcement and as strengthening of structures. Steel reinforcement as compared to (FRP) reinforcement are decreasingly acceptable for structural concrete reinforcement including precast concrete, cast in place concrete, columns, beams and other components. Carbon Fiber Reinforcement Polymer (CFRP) have a very high modulus of elasticity "high modulus" and very high tensile strength. In aerospace industry, CFRP with high modulus are popular among all FRPs because it has a high strength to weight ratio. In this research, a finite element models will be used to represent beams with Carbon Fiber Reinforcement and beams with steel reinforcement. The primary objective of the research is the evaluation of the effect of (CFR) on beam reinforcement.
\end{abstract}

\section{Introduction}

Recently, carbon FRP bars were developed. These CFRP bars provide a comparable performance to that of conventional steel bars. In between of the various types of fiber reinforcement polymer, (Carbon Fiber Reinforcement Polymer) has the highest tensile modulus of elasticity. There are serious problems faced by concrete elements reinforced with normal steel, so CFRP internal reinforcement bars have been developed with the advantages below:

- $\quad$ CFRP bars do not corrode

- $\quad$ CFRP bars are light weight

- CFRP bars are high strength

This material is suitable for structural applications because of high strength to self-weight ratio, low own weight, electromagnetic transparency, high resistance against corrosive agents, along with the other recommend structural and technologic parts. Disadvantages in the global use of these materials are the high cost of initial application, high cost of manufacturing these materials and the main disadvantage of this material is the lack of standard national design codes [1].

\section{Research significance}

Evolution of reinforcement technology is going to be very progressive because engineers design will not employ concrete reinforced with steel. In the last years, one of the very important materials in reinforced concrete which has been suggested was Fiber Reinforced Polymer (FRP). The reinforcement of fiber polymer is very modern and limited to some works on structures, it increases the full capacity of reinforced concrete beams, enhances the tensile strength and reduces deflection but the utilization of carbon fiber reinforcement is very low and it is very expensive. Carbon fiber reinforcement polymer can be produced with higher strength and modulus of elasticity than steel, then the structural members will improve in flexure, shear strength, and deflection. The study aims to investigate the effect of carbon fiber bars on the reinforced concrete beams. Finite element approach was used to simulate the beam reinforced with CFRP bars then compare the results with analytical solution [6].

\section{Historical review}

One of the popular materials for building construction in the world is reinforced concrete. Reinforced concrete has been used as main material construction in many structures such as bridges and buildings. Concrete lacks tensile strength but the common reinforcement in tensile strength use in reinforced concrete is steel. Though performance of steel is excellent in reinforcement of concrete but it has some problems. Steel tends to crumble fast, especially when expose to sea water and extreme coastal weather. In 2013, Norazman Mohamad Nor et al [3], investigated an alternative reinforcement for concrete structures which is non-metal called "Carbon fiber reinforced polymer CFRP". Actually, 
(CFRP) is being used for damaged structures due to long age or due to exposure to bad weather conditions and for structural repair. The aim of their study, is to increase the tensile strength of reinforced concrete, replacing steel reinforcement, completely and using (CFRP) instead. The most important advantage of using (CFRP) in reinforcement is to avoid reinforcement corrosion and reinforcement rusting. In 2002, Padmarajaiah and Ramaswamy [4], illustrated the results of increasing concrete compressive strength by adding fibers. They increased the concrete compressive strength up to $(15 \%)$ from normal strength by adding fibers up to $1.5 \%$ in volume. So, the concrete compressive strength and concrete strain affected by fibers volume. In 2008 , Ţăranu Nicolae et al [1], have presented two main issues, using internal reinforcements of FRP composite materials for new members in the structure and strengthening of existing members (externally bonded reinforcements). The advantages, disadvantages, constraints as well as the problems associated are mainly related to concrete members.

\section{Properties of Materials}

In this paper five finite element models were built up using ANSYS software [5] to simulate reinforced concrete beams with traditional reinforcement, CFRP bars, and both were investigated. Model's materials and properties are listed in Table (1). All beams have the same geometry of concrete. The parameters considered are shown in Table (2).

Table 1. Materials properties

\begin{tabular}{|c|c|c|c|c|c|}
\hline \multicolumn{2}{|c|}{ Concrete } & \multicolumn{2}{c|}{ Steel bars } & \multicolumn{2}{c|}{ CFRP bars } \\
\hline fć & $31 \mathrm{MPa}$ & fy & $414 \mathrm{MPa}$ & $\mathrm{fy}_{(\text {CFRP) }}$ & $\begin{array}{c}3690 \\
\mathrm{MPa}\end{array}$ \\
\hline $\mathrm{E}_{\mathrm{C}}$ & $\begin{array}{c}26168 \\
\mathrm{MPa}\end{array}$ & $\mathrm{E}_{\mathrm{S}}$ & $\begin{array}{c}200000 \\
\mathrm{MPa}\end{array}$ & $\mathrm{E}_{(\text {CFRP) }}$ & $\begin{array}{c}580000 \\
\mathrm{MPa}\end{array}$ \\
\hline$v_{\mathrm{c}}$ & 0.15 & $v_{\mathrm{s}}$ & 0.3 & $v_{(\mathrm{CFRP})}$ & 0.3 \\
\hline
\end{tabular}

Where,

fć: Cylinder compressive strength of concrete.

$\mathrm{E}_{\mathrm{C}}$ : Concrete modulus of elasticity.

$v_{\mathrm{c}}$ : Poisson's ratio of concrete.

fy: Steel yield strength.

$\mathrm{E}_{\mathrm{S}}$ : Steel modulus of elasticity.

$v_{\mathrm{s}}$ : Poisson's ratio of steel.

$\mathrm{fy}_{\text {(CFRP: }}$ Yield stress carbon for fiber reinforcement polymer.

$\mathrm{E}_{\text {(CFRP): }}$ Modulus of elasticity for carbon fiber reinforcement polymer.

$v_{\text {(CFRP) }}$ : Poisson's ratio for carbon fiber reinforcement polymer.
Table 2. Types of beams considered in the analysis

\begin{tabular}{|c|c|c|c|c|}
\hline \multirow{2}{*}{$\begin{array}{c}\text { Beam } \\
\text { no. }\end{array}$} & \multicolumn{3}{|c|}{ Reinforcement Bars } & \multirow{2}{*}{$\begin{array}{c}\text { Method of } \\
\text { Analysis }\end{array}$} \\
\cline { 2 - 4 } & Main & Top & Stirrups & Linear \\
\hline B1 & steel & steel & steel & Nonlinear \\
\hline B2 & steel & steel & steel & Nor \\
\hline B3 & CFRP & CFRP & CFRP & Linear \\
\hline B4 & CFRP & steel & steel & Linear \\
\hline B5 & CFRP & CFRP & CFRP & Nonlinear \\
\hline
\end{tabular}

\section{Geometric modelling}

(SOLID65) Element is used for the (3-D) modeling of solids (with or without) reinforcement bars. (SOLID65) element is qualified for crushing in compression and cracking in tension. The solid ability of the element may be used for modeling the concrete while the rebar ability is available for modeling the behavior of reinforcement in concrete applications. (SOLID65) shown in (Figure 1) which is defined by eight nodes and each node has three degrees of freedom: translations in the nodal $(\mathrm{x}, \mathrm{y}$, and $\mathrm{z}$ directions). May be defined up to three different rebar specifications. The treatment of properties for nonlinear material is the most important part in this element. Concrete is capable of cracking in three orthogonal directions, crushing, plastic deformation, and creep. The rebar are not capable of shearing but they are capable of compression and tension. The rebar are also capable of creeping and plastic deformation. Below are the elements which were used to model the concrete.

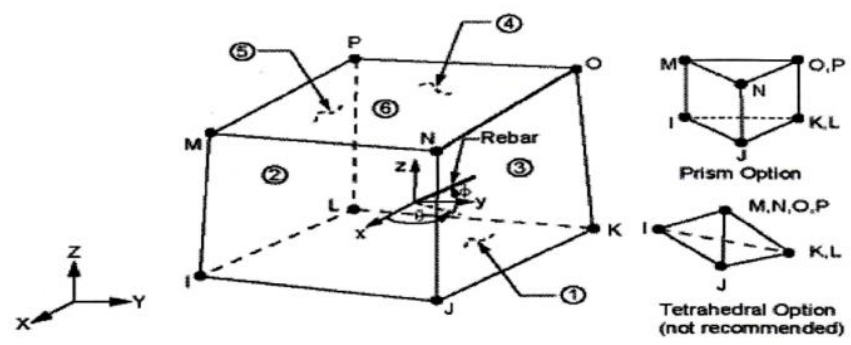

Fig.1. SOLID65 element geometry

Table 3. Materials Representations

\begin{tabular}{|c|c|c|}
\hline $\begin{array}{c}\text { Element } \\
\text { Number }\end{array}$ & Element Type & Representation \\
\hline 1 & SOLID65 & Concrete cross section \\
\hline 2 & LINK8 & $\begin{array}{c}\text { Top and bottom } \\
\text { longitudinal reinforcement }\end{array}$ \\
\hline 3 & LINK8 & Stirrups and CFRP bars \\
\hline
\end{tabular}




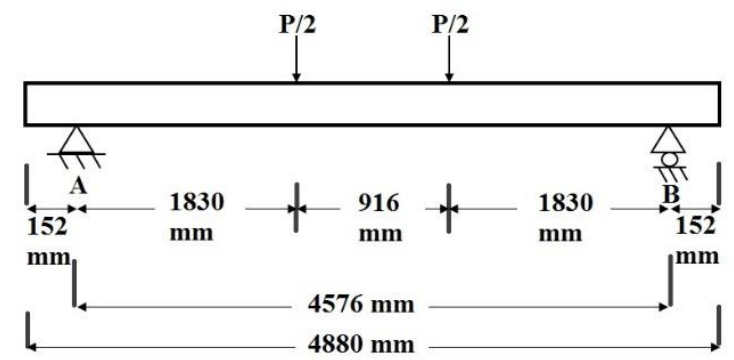

Fig.2. Beam dimensions

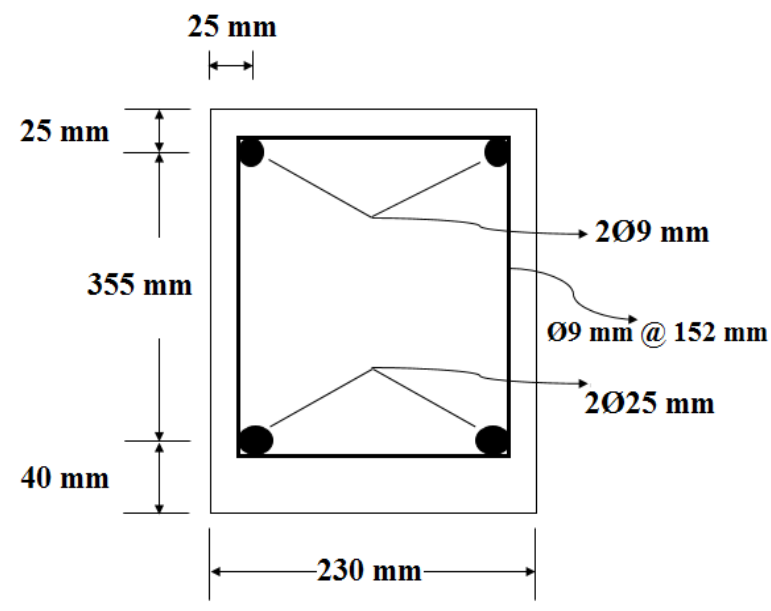

Fig. 3. Beam cross section

Table 4. Reinforcement bars details

\begin{tabular}{|c|c|}
\hline Reinforcement & Details \\
\hline $\begin{array}{l}\text { Bottom (main } \\
\text { reinforcement) }\end{array}$ & 2 bars $\varnothing 25 \mathrm{~mm}$. \\
\hline $\begin{array}{l}\text { Top (secondary } \\
\text { reinforcement) }\end{array}$ & 2 bars $\varnothing 9 \mathrm{~mm}$. \\
\hline Stirrups & $\begin{array}{c}\text { Ø9 mm@ } 152 \mathrm{~mm} \text {. center to } \\
\text { center }\end{array}$ \\
\hline
\end{tabular}

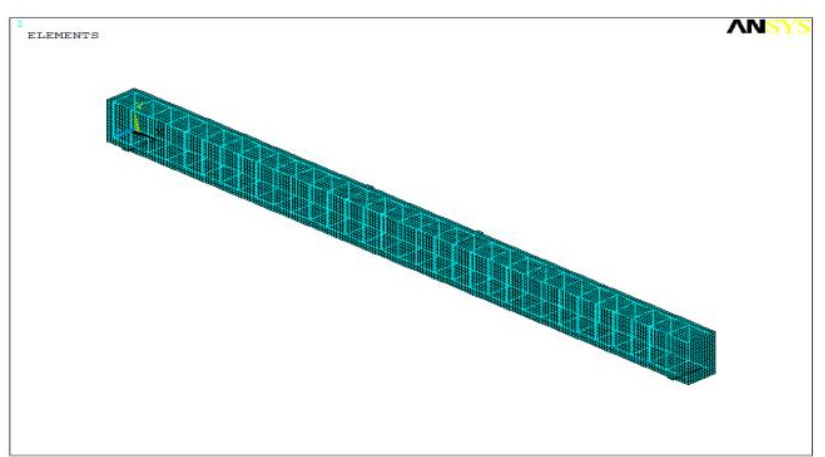

Fig. 4. Beam reinforcement ANSYS model

\section{Beams deflection}

The deflection of beams was calculated by taking deflection results of beams tested in the laboratory [2], and then compared these results using the same loading with hand out calculation by applying the theoretical approach described in (ACI 318M -14) [6]. Finite element models were representing beams and calculate the deflection at midspan beam. Table (5) show models deflection results at load level $196 \mathrm{kN}$.

Table 5. Models deflection results

\begin{tabular}{|c|c|c|c|}
\hline Beam & $\begin{array}{c}\text { Applied } \\
\text { Load (kN) }\end{array}$ & $\begin{array}{c}\text { Ultimate } \\
\text { Deflection at } \\
\text { Midspan (mm) }\end{array}$ & $\begin{array}{c}\% \text { Reduction } \\
\text { of Deflection }\end{array}$ \\
\hline B1 (linear) & 196 & 23.51 & $\begin{array}{c}100 \% \\
\text { (reference) }\end{array}$ \\
\hline B3 (linear) & 196 & 11.21 & $52 \%$ \\
\hline B4 (linear) & 196 & 11.67 & $50 \%$ \\
\hline $\begin{array}{c}\text { B2 } \\
\text { (nonlinear) }\end{array}$ & 196 & 45 & $\begin{array}{c}100 \% \\
\text { (reference) }\end{array}$ \\
\hline $\begin{array}{c}\text { B5 } \\
\text { (nonlinear) }\end{array}$ & 196 & 11.28 & $74 \%$ \\
\hline
\end{tabular}

Figures (5, 6 and 7) represent relationship between beams loading and beams deflection, while Figures ( 8 and 9) show beams deflection and beams cracks captures by ANSYS program. 


\section{Results discussion}

- Because of the yielding \& modulus of elasticity of CFRP material the deflection are performed $\%$ reduction to $(52 \%$ linearly and $74 \%$ nonlinearly) instead of the traditional reinforcement steel.

- The (stress-strain) curve for traditional reinforcement steel assumed to be (elasticperfectly plastic) but CFRP behavior is assumed to be linear according to the assumption recommended by (ACI 440-2R-06) [7].

- In simply supported beam, the main factor affecting deflection is the main reinforcement, modulus of elasticity and the geometry of beam because of it is function of compressive strength. The modulus of elasticity and the geometry of beam assumed to be constant so that in present study the main reinforcement of CFRP is more effective than stirrups and secondary top reinforcement.

- In beam B2, the nonlinear of steel reinforcement assumed elastic - full plastic behavior. Applied load $(196 \mathrm{kN})$ has not reached as a full loading. Because of the cracked zone at tension faced due to increased loading due to the nonlinearity of reinforcement and reached to the plastic zone, the deflection became more so that at $80 \%$ of applied loading the deflection $45 \mathrm{~mm}$ as shown in Figure (5), but at full load the deflection became $125 \mathrm{~mm}$.

- Analytical solution for steel reinforcement with maximum deflection equal to $(23.373 \mathrm{~mm})$ and maximum deflection equal to $(23.511 \mathrm{~mm})$ as numerical solution as shown in Figure (10), so that the ratio between them equal to (1.006) and the difference ratio equal to $(0.59 \%)$ which is acceptable because it is less than $(10 \%)$ for the design of the reinforced concrete beam.

- Analytical solution for CFRP reinforcement with maximum deflection equal to $(10.261 \mathrm{~mm})$ and maximum deflection equal to $(11.215 \mathrm{~mm})$ as numerical solution as shown in Figure (11), so that the ratio between them equal to (1.09) and the difference ratio equal to $(8.5 \%)$ which is acceptable because it is less than $(10 \%)$ for the design of the reinforced concrete beam. 


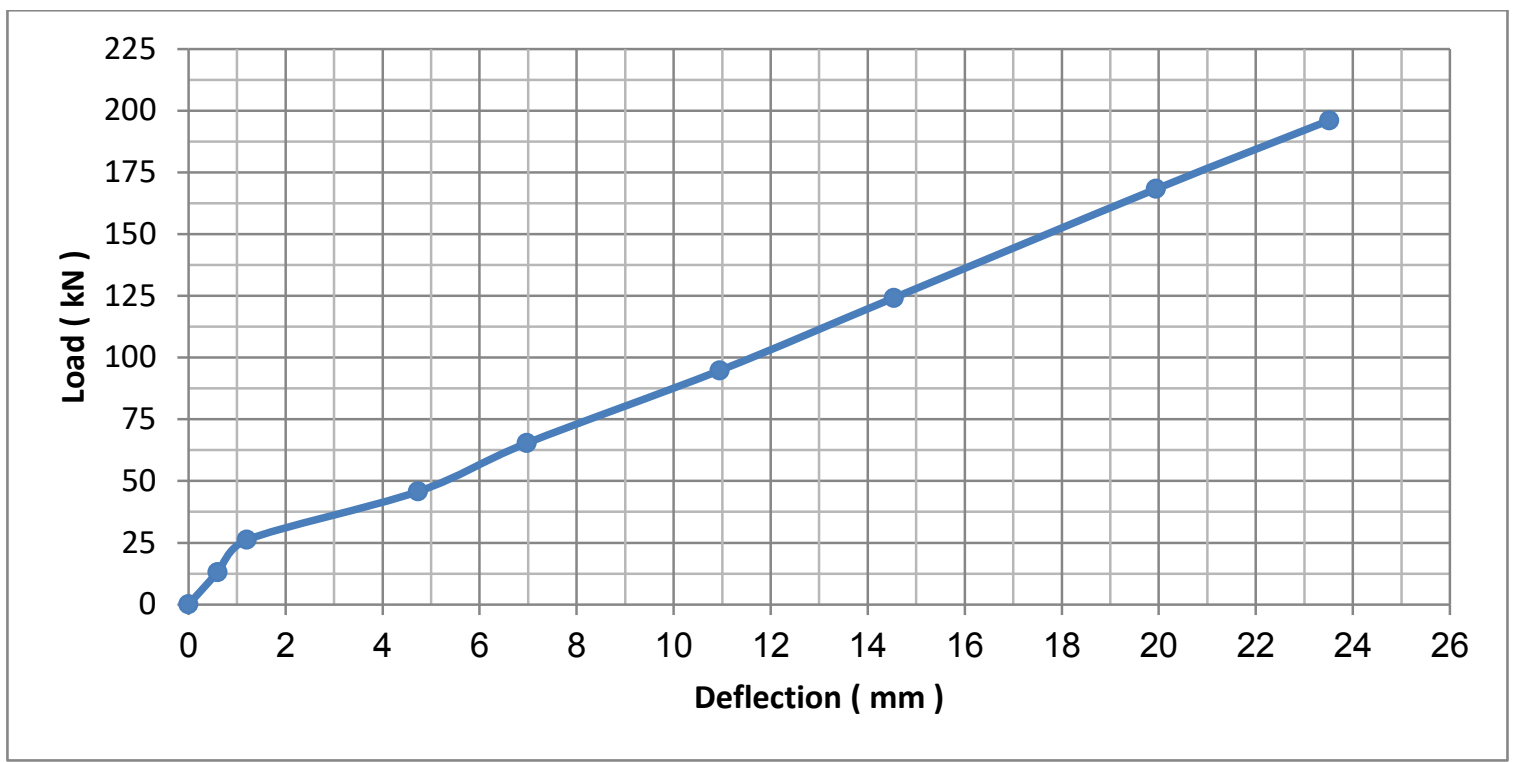

(a) Linear performance of B1 (Steel Reinforcement)

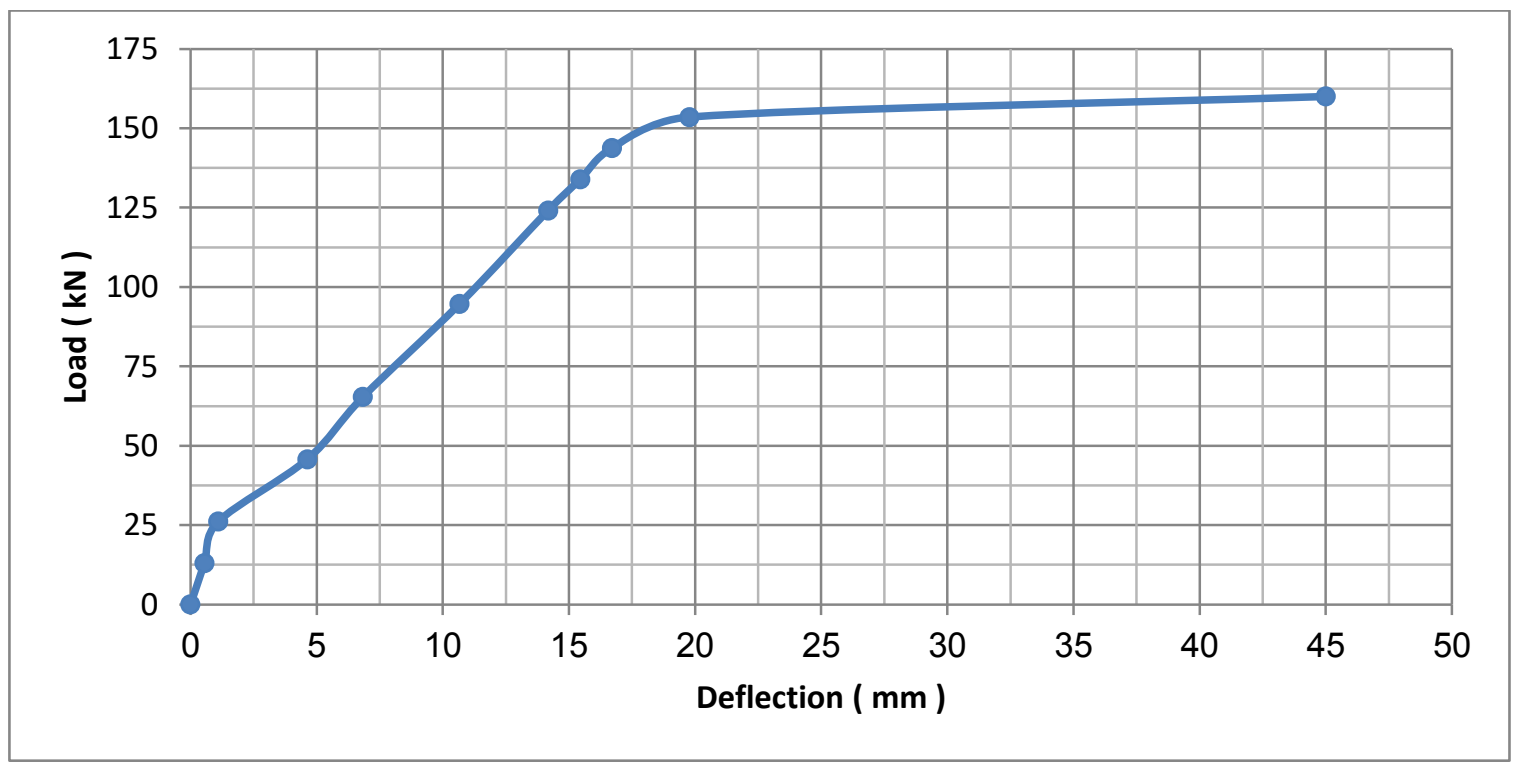

(b) Nonlinear performance of B2 (Steel Reinforcement)

Fig. 5. Load-midspan deflection relation of beams with steel reinforcement 


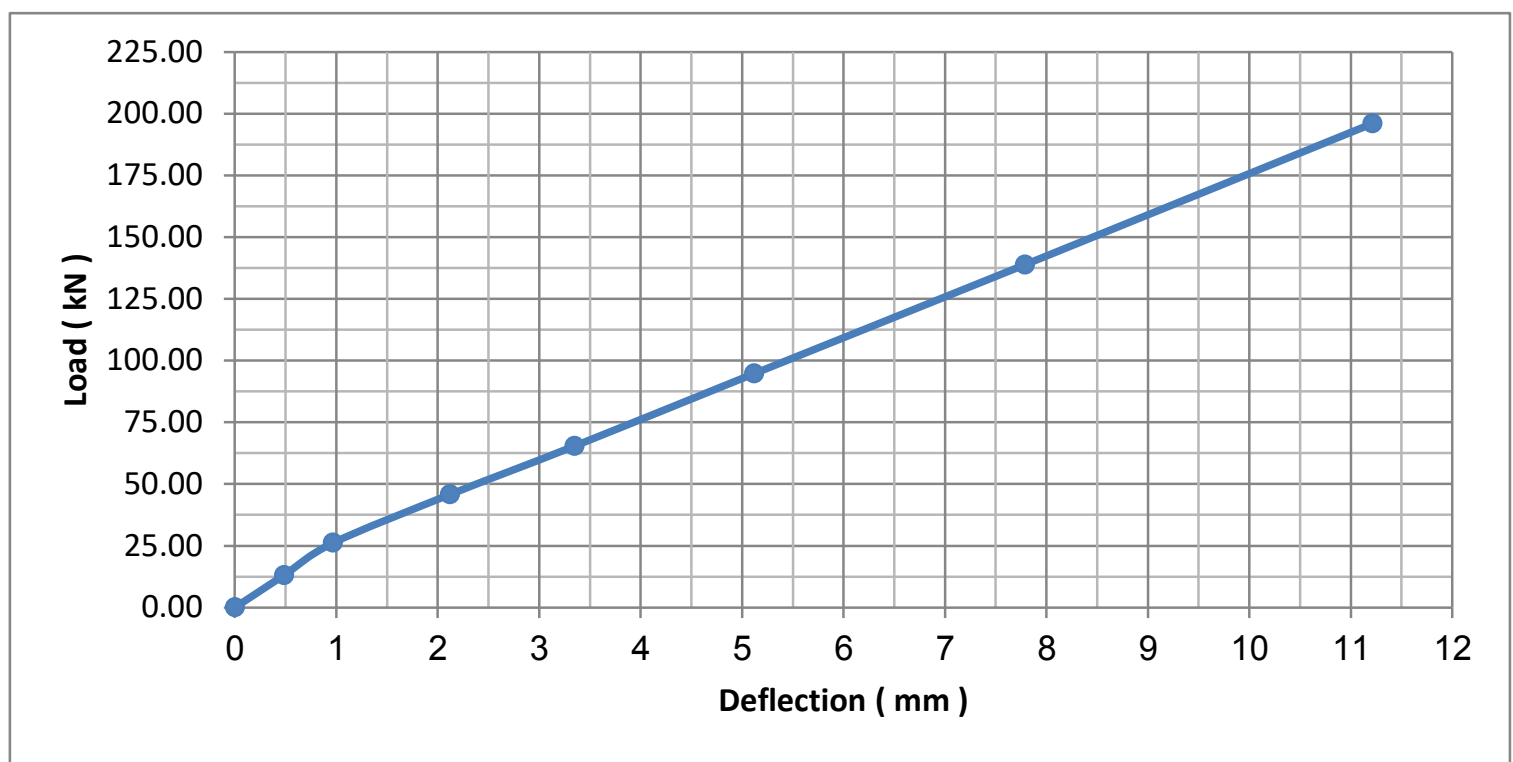

(a) Linear performance of B3 ( CFRP reinforcement)

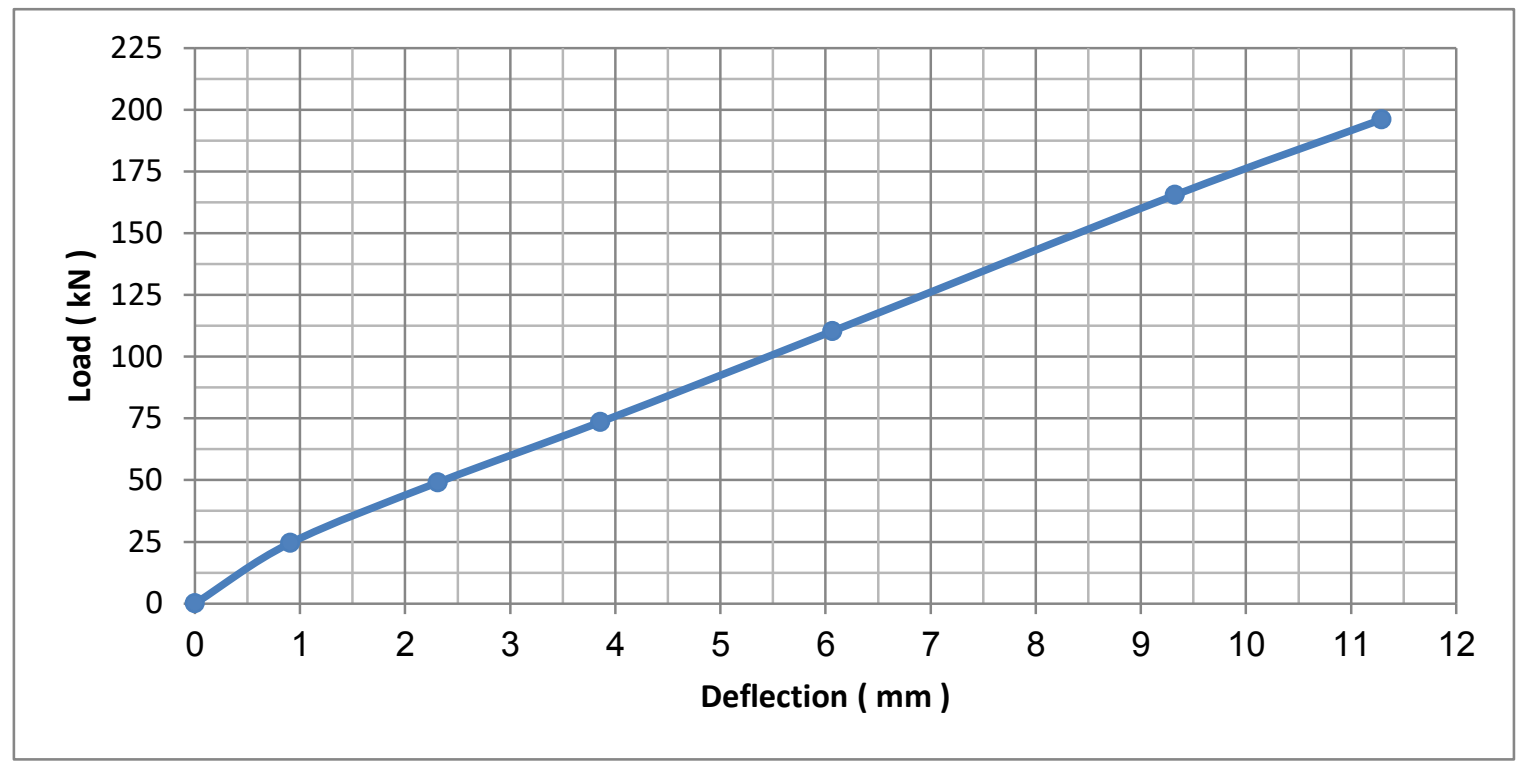

(b) Nonlinear performance of B5 (CFRP reinforcement)

Fig. 6. Load-midspan deflection relation of beams with CFRP reinforcement 


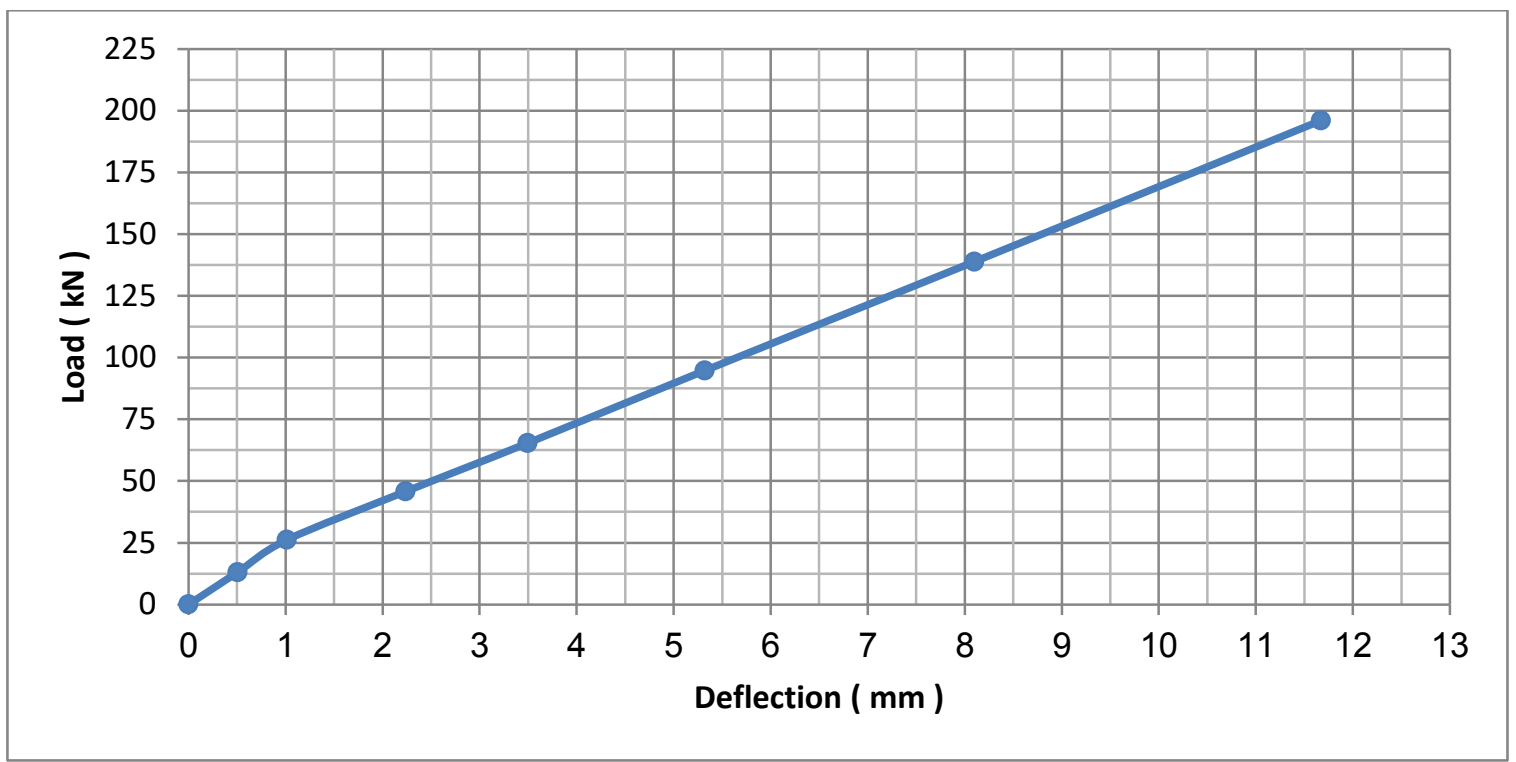

Linear performance of B4 (CFRP main reinforcement, steel top reinforcement and steel stirrups)

Fig. 7. Load-midspan deflection relation of beam with Steel and CFRP reinforcement

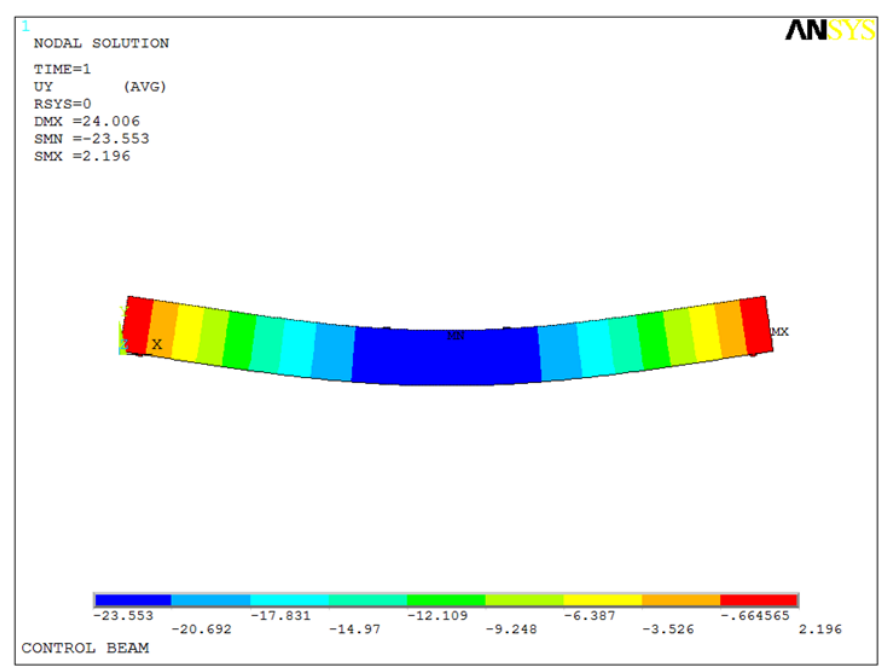

B1 deflection

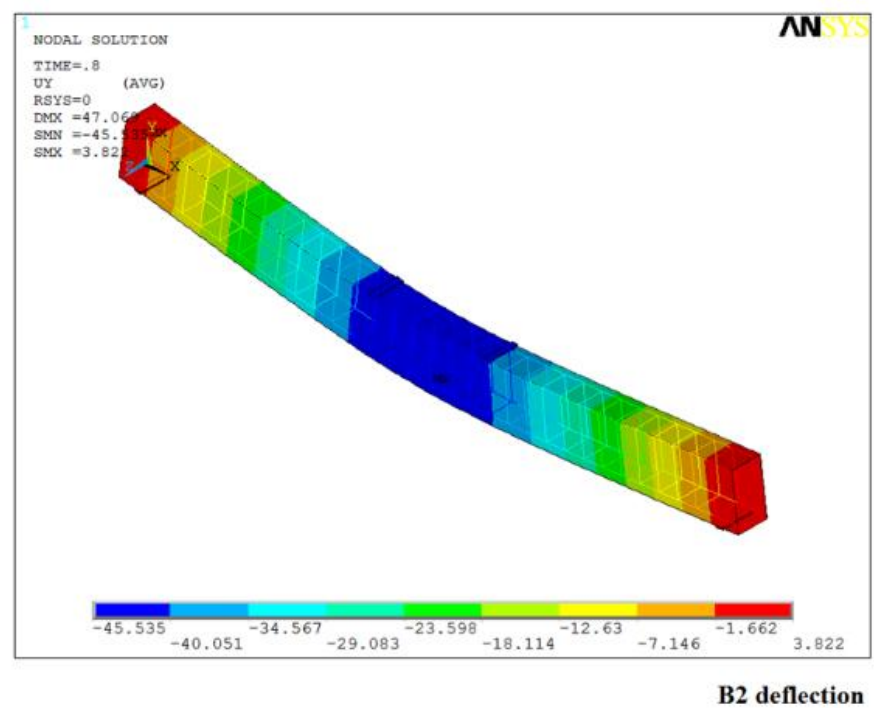

Fig. 8. Deflection of beams 1 and 2 captured by ANSYS 


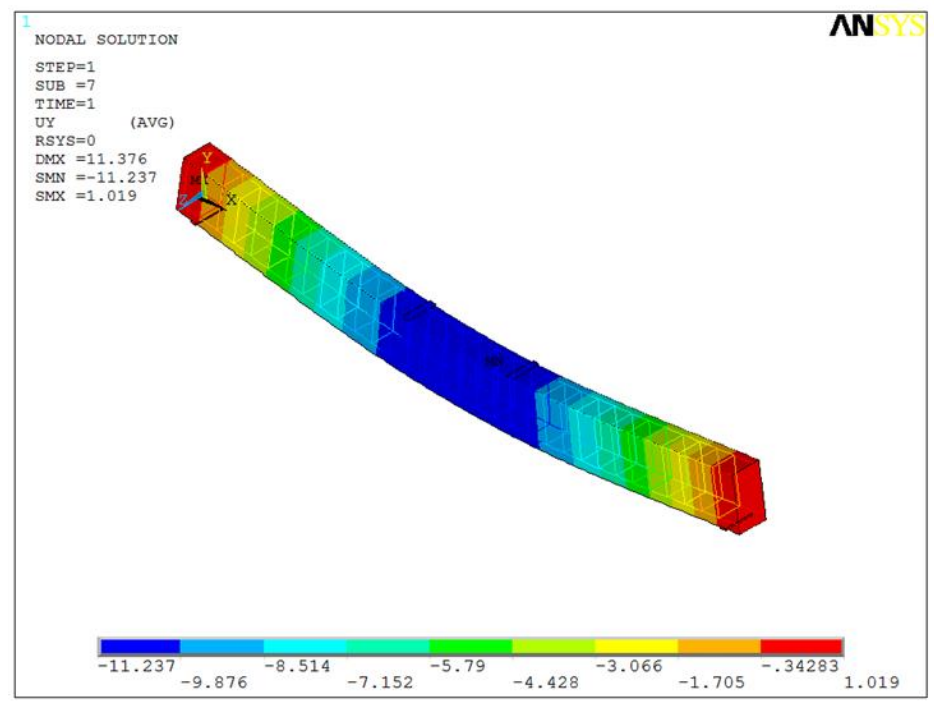

B3 deflection

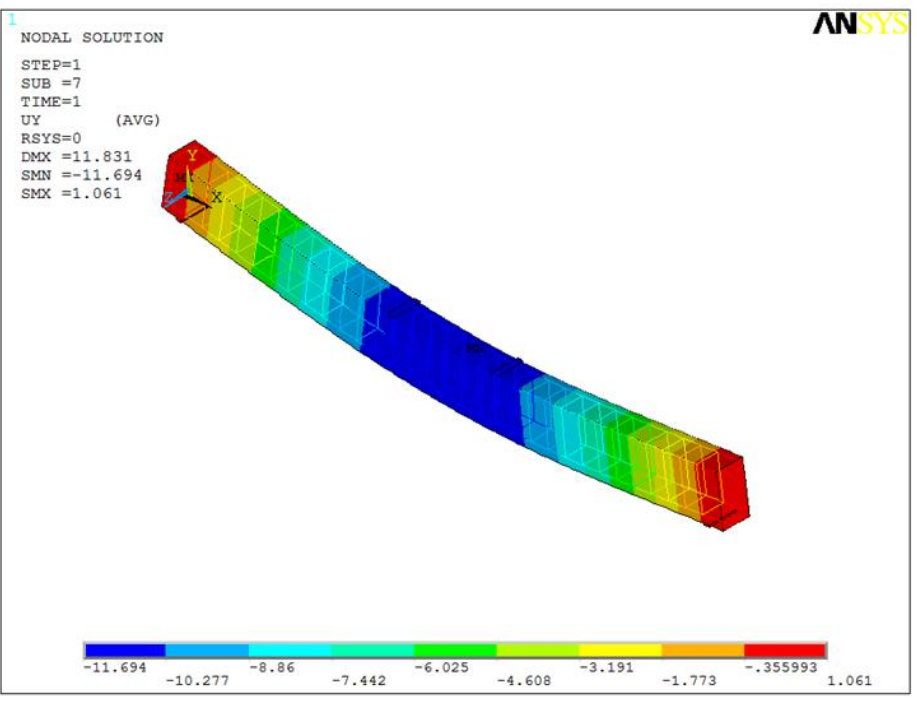

B4 deflection

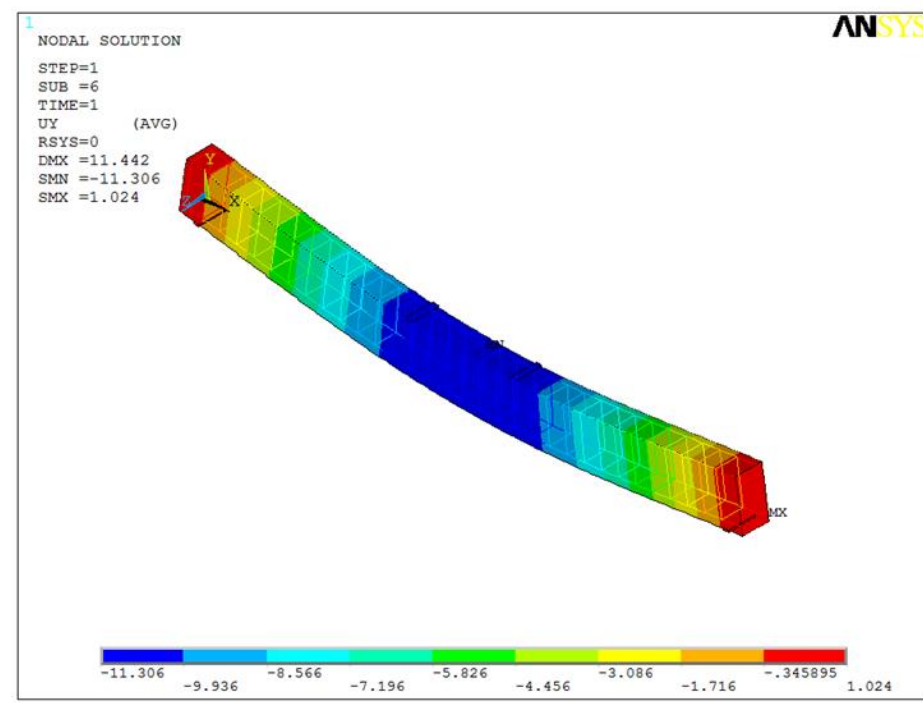

B5 deflection

Fig. 9. Deflection of beams 3, 4 and 5 captured by ANSYS 


\section{References}

1. T. Nicolae, O. Gabriel, I. Dorina, E. Ioana, M. Vlad, B. Cătălin, Universitatea Tehnică, 1, 7-20 (2008)

2. P. Alagusundaramoorthy, I. E. Harik C. C. Choo, Research report, College of Engineering, University of Kentucky, Frankfort, KTC-0213/SPR 200-99-1F, (Aug.2002)

3. N. M. Nor, M. H. A. Boestamam and M. A. Yusof, International Journal of Emerging Technology and Advanced Engineering, Malaysia, 3, 2, 6-10, (Feb.2013)

4. S. K. Padmarajaiah, A. Ramaswamy, Journal of Material in Civil Engineering 14, 2, 130-136 (Mar.2002)

5. ANSYS: Inc. is a UL registered ISO 9001:2000 Company. Release 11.0SP1 UP20070830. ANSYS Multiphysics. Manual help, USA

6. Building Code Requirements for Structural Concrete and Commentary. ACI 318M-14. Farmington Hills, MI: American Concrete Institute, 503pp. (2014)

7. Guide for the Design and Construction of Structural Concrete Reinforced with FRP Bars. ACI 440.1R-06: American Concrete Institute, 44pp. (2006) 